\title{
Antioxidant and antimicrobial activities of squid ink powder
}

\author{
Fatimah Zaharah, M.Y. and *Rabeta, M.S. \\ Food Technology Division, School of Industrial Technology, Universiti Sains Malaysia, 11800 Minden, \\ Penang, Malaysia
}

\begin{abstract}
Article history:
Received: 13 September 2017

Received in revised form: 27

September 2017

Accepted: 29 September 2017

Available Online: 2 October

2017

Keywords:

Squid ink,

Antioxidant,

Antimicrobial
\end{abstract}

DOI:

https://doi.org/10.26656/fr.2017.2(1).225

\begin{abstract}
Economic development in Malaysia has led to increasing quantity and complexity of generated waste or by-product. The main objective of this study is to investigate the antioxidant and antimicrobial activities of squid ink powder. The squid ink was collected from fresh squid and dried using freeze dryer before it was ground into powder. The yield of squid ink was $22.82 \%$ after freeze-drying which was $69.37 \mathrm{~g}$ in amount. Proximate composition analysis as well as two total antioxidant activity assays named 2,2-diphenyl-1 -picrylhydrazyl (DPPH) assay and Ferric Reducing Antioxidant Power (FRAP) assay, and antimicrobial analysis were done on the powdered squid ink. The proximate results of squid ink powder were $4.43 \pm 0.29 \%$ moisture, $62.46 \pm 0.62 \%$ protein, $3.96 \pm 0.08 \%$ fat, and $9.29 \pm 0.05 \%$ ash. Results of DPPH assay showed that water extraction of squid ink powder has the highest $94.87 \pm 4.87 \%$, followed by ethanol $67.57 \pm 7.55 \%$, and hexane extract $2.10 \pm 1.18 \%$. FRAP assay result presented the same trend with water extraction had the highest value of $929.67 \pm 2.31 \mu \mathrm{mol} F e$ (II) / g of sample extract, followed by ethanol extract $201.00 \pm 26.29 \mu \mathrm{mol} F$ (II) per gram sample and hexane $79.67 \pm 12.66$ $\mu \mathrm{mol} \mathrm{Fe}$ (II) / g of sample extract. Both water and ethanol extract showed antimicrobial properties with inhibition range of 7 to $15 \mathrm{~mm}$, respectively. Fresh squid ink had $1.254 \times$ $10^{3}$ colony forming unit per gram of sample of microbial content. Squid ink powder had protein as major compound and microbial content was below from standard value of fisheries products as stated in Food Act 1983 and Regulation 1985.
\end{abstract}

\section{Introduction}

Huge innovation opportunities exist in using an underutilized/waste/by-product to create new healthy products to consumers. In the $21^{\text {st }}$ century, consumer interest in healthy eating is shifting towards the potential health benefits beyond basic nutrition. The beyond functions are not performed by nutrients in foods, but rather by other components in food (Tee, 2013). Generally, functional foods look the same to conventional foods (Cencic and Chingwaru, 2010). Functional food should be, or look like, a traditional food and must be part of our daily diet (The European Scientific Community, 2010).

Squid, cuttlefish, and octopus are major seawater catch other than fishes and prawns. These seawater products are grouped under phylum of invertebrate animals known as Mollusca and family of Cephalopoda. Cephalopods are common and important in Malaysia fisheries in terms of domestic consumption and economic values (Rubaie et al., 2011). They are mainly exported, so large amounts of waste and unutilized materials are produced (e.g., squid ink sacks).

Ink sacs have attracted considerable attention, both casually and scientifically, because of their dramatic black color (Derby, 2014). Squid and cuttlefish ink was produced at the end process of maturation in a viscous, colorless medium (Liu et al., 2011). Humans have used cephalopod ink for many practical and commercial purposes over the millennia, particularly in medicine, cuisine, and art, as well as in even broader applications (Derby, 2014). This by-product can be a potential source of good bioactive compounds (Vate and Benjakul, 2013).

Free radicals are the unstable molecule that can damage the cells. This cell damage may lead to various sicknesses like cancer, heart disease, cataracts, diabetes or infections (American Dietetic Association, 2010). For 
the past few decades, a major transition in disease patterns from acute illness to chronic non-communicable diseases such as cardiovascular disease, diabetes mellitus, and cancer were due to unhealthy diet intake (Ministry of Health Malaysia, 2010). Natural antioxidants from marine resources, especially from the by-products of seafood processing, can be another alternative antioxidant for food application (Vate and Benjakul 2013). Based on a research by Liu et al. (2011) on broiler chickens, the growth performance, antioxidant functions as well as immunity was affected by squid ink. A study of Girija et al. (2014) suggested that squid ink has antibacterial potentials against the dental caries pathogens.

The extracts from these solvents were then tested in terms of antioxidant 2,2-diphenyl-1-picrylhydrazyl (DPPH) and Ferric Reducing Antioxidant Power (FRAP) antimicrobial activities. Other analyses are included microbial content determination and proximate analysis.

\section{Materials and methods}

\subsection{Collection and sample preparation}

Sample with the same size and physical appearance was collected in Taman Tun Saadon Wet Market near Gelugor, Penang, Malaysia during the end of December 2014 until the end of March 2015. Pictures of the samples were taken and sent to Dr. Amir Shah Ruddin bin Md. Sah from School of Biology, USM, for species identification. The squid was identified as Loligo duvauceli which is commonly known as Indian Squid. Freshly obtained squids were dissected and ink glands were manually removed from the viscera. The ink glands were then placed in clean plastic containers before placing them in the blast freezer. The frozen ink glands later entered the freeze dry (Millrock Technology, NY, USA) to drain out the water (lyophilization process) and retain the compound in the sample. The freeze-dried ink was ground to a fine powder with the use of an electric grinder and kept in an airtight plastic container. The container was then covered with aluminum foil to prevent any light to penetrate through. The samples were stored in a freezer at $-20^{\circ} \mathrm{C}$ before further analysis were made.

\subsection{Sample extraction}

Sample was extracted with modification according to the method by Ikram et al. (2009) where the extract was obtained by mixing $0.5 \mathrm{~g}$ of sample with $50 \mathrm{ml}$ of $70 \%$ ethanol $(\mathrm{v} / \mathrm{v})$ in conical flask wrapped with aluminum foil to prevent any loss of the solvent as well as to avoid direct light from penetrating the extract. The mixture was then shaking in an orbital shaker (Lab companion, Model SI600R) for overnight at $160 \mathrm{rpm}$ and $27^{\circ} \mathrm{C}$. The mixture was then centrifuged in a centrifugal (Kubota, Model 4000) at $2500 \mathrm{rpm}$ for $30 \mathrm{~min}$ to obtain a clear solution. These steps were repeated using distilled water and $60 \%$ hexane $(v / v)$ for extraction.

\subsection{Proximate composition}

Proximate analysis of the samples, which include moisture content, ash, crude protein, fat, and crude fiber, was determined according to the methods set forth by the Association of Analytical Chemist (AOAC) 2000. Percentage of carbohydrate content was determined by the following formula:

$\%$ Carbohydrate $=100-(\%$ ash $+\%$ fat $+\%$ protein $+\%$ fiber content)

\subsection{2, 2-Diphenyl-1-Picrylhydrazyl (Dpph) assay}

This method was adapted and modified from Sánchez-Moreno et al.'s study (1998). About $2 \mathrm{ml}$ of sample extract (in ethanol, distilled water, and hexane) was mixed with $2 \mathrm{ml}$ of $100 \mu \mathrm{mol} / \mathrm{L}$ DPPH solution (ratio 1:1). Blank or control was prepared as $2 \mathrm{ml}$ of distilled water mixed with $2 \mathrm{ml}$ of $100 \mu \mathrm{mol} / \mathrm{L} \mathrm{DPPH}$ solution. The contents were mixed vigorously using vortex shaker and allowed to stand at room temperature for $30 \mathrm{~min}$ in the dark. The absorbance was measured at $516 \mathrm{~nm}$ by using UV-Vis spectrophotometer (Shimadzu UV-Visible Recording Spectrophotometer, Model UV160A) against blank. The results obtained were calculated and expressed in the term of percentage value (\%) of DPPH free radical scavenging activity by using the equation:

$\%$ of DPPH free radical scavenging activity $=\frac{\text { ABS control-ABS sample }}{\text { ARS } \mathrm{mntmol}} \times 100$

Where,

ABS control: Absorbance of blank/control

ABS sample: Absorbance of sample

\subsection{Ferric reducing antioxidant power (frap) assay}

This antioxidant analysis was done according to Benzie and Strain's study (1996) with some modifications. This method measures the ability of extracts to reduce ferric ions. FRAP reagent was freshly prepared by mixing $100 \mathrm{ml}$ of acetate buffer $(0.3 \mathrm{M}, \mathrm{pH}$ 3.6), $10 \mathrm{ml}$ of 2,4,6-tri(2-pyridyl)-1,3,5-triazine (TPTZ) solution $(10 \mathrm{mM}$ in $40 \mathrm{mM} \mathrm{HCl})$ and $10 \mathrm{ml}$ of $\mathrm{FeCl}_{3} \cdot 6 \mathrm{H}_{2} \mathrm{O}(20 \mathrm{mM})$ solution. Approximately $200 \mu \mathrm{L}$ of the extract was mixed together with FRAP reagent for 30 min in dark condition to obtain a proper and even 
reaction. A blank was prepared using distilled water. Readings of colored products were obtained using UVVis spectrophotometer (Shimadzu UV-Visible Recording Spectrophotometer, Model UV-160A) at $593 \mathrm{~nm}$ wavelength.

\subsection{Media used and preparation in microbial analysis}

Plate count agar culture used media nutrient agar and peptone water. The media was prepared by following the manual on the bottle and placed in media bottle before autoclave. The autoclave process was taking time about $15 \mathrm{~min}$ at $121^{\circ} \mathrm{C}$ temperature and 15 psi pressure.

\subsection{Total plate count analysis}

A total of $25 \mathrm{~g}$ of sample was mixed with $225 \mathrm{ml}$ of peptone water and then homogenized well. By using sterile pipettes, about $10 \mathrm{ml}$ of homogenized sample was transferred into $90 \mathrm{ml}$ of diluents or peptone water in a universal bottle and decimal dilutions were prepared (10 $\left.{ }^{2}, 10^{-3}, 10^{-4}\right)$. All dilutions were shaken, and about $1 \mathrm{ml}$ was transferred into a sterile petri dish. Duplicates for each dilution were prepared. About $15 \mathrm{ml}$ to $20 \mathrm{ml}$ of nutrient agar (cooled to $45 \pm 1{ }^{\circ} \mathrm{C}$ ) was added to each plate, and sample dilutions were immediately mixed with agar thoroughly and uniformly through rotating and back -forth movement with the plate on a flat surface. The agar with sample dilution is left to solidify. The solidified petri dishes were inverted and incubated for 48 $\pm 2 \mathrm{~h}$ at $35^{\circ} \mathrm{C}$. After the incubation, all colonies growth was calculated and represented as colony forming unit (CFU).

\subsection{Media used and preparation in antimicrobial analysis}

Media used for antimicrobial analysis was MuellerHinton Agar. The agar was prepared according to the manual stated on the bottle. The prepared agar, after sterilization process, was poured into sterile petri dishes about 15 to $20 \mathrm{ml}$ to solidify. The antimicrobial disc was prepared by using Whatman filter paper where the extract containing antimicrobial properties was immersed together prior being used. The disc was stored in a universal bottle and covered with aluminum foil before sterilized using autoclave. The sterilized discs were stored at freezer before used.

\subsection{Inoculum preparation}

Microorganisms used in the antimicrobial analysis were including Staphylococcus aureus, Escherichia coli, Salmonella $s p$, and Bacillus subtillis. All of these microorganisms were obtained from microbiology laboratory of Food Division at School of Industrial Technology, USM. Confirmation test was applied on each microorganism of interest before used in the analysis (Clinical and Laboratory Standards Institute 2014). The microorganisms were cultured in nutrient broth and incubated until turbidity of broth was equivalent 0.5 McFarland standards.

\subsection{Disc diffusion assay}

The analysis of antimicrobial properties was started by dipping a sterile cotton swab into adjusted suspension. The cotton swab was rotated in the suspension and pressed on the wall of the universal bottle to remove excess fluid. The cotton swab with suspension was spread on Mueller-Hinton agar surface and repeated twice to ensure an even distribution of inoculum. The disc containing antimicrobial compound was pressed on the surface of agar to ensure a complete contact. Other discs were placed evenly on the agar surface giving enough surrounding for microorganism inhibition. The petri dish with inoculum and the antimicrobial disc was inverted and incubated at $35 \pm 2^{\circ}$ $\mathrm{C}$ for 16 to $18 \mathrm{~h}$. Inhibition zone formed after incubation time was measured and recorded.

\subsection{Statistical analysis}

Results were reported as means \pm standard deviation (SD) for triplicate determinations. Analysis of variance and the significant differences between mean values were determined by using Duncan test at a level of significance of $\mathrm{p}<0.05$. Statistical analyses were conducted by using SPSS 22.0 (SPSS for Windows, 2007, SPSS Inc., Chicago, USA).

\section{Results}

\subsection{Proximate analysis of squid ink powder}

Table 1. Proximate composition in squid ink powder

\begin{tabular}{cc}
\hline Proximate analysis & Results (\%) \\
\hline Moisture & $4.43 \pm 0.29$ \\
Crude Protein & $62.46 \pm 0.62$ \\
Crude Fat & $3.96 \pm 0.08$ \\
Ash & $9.29 \pm 0.05$ \\
\hline
\end{tabular}

Table 1 showed the overall results of proximate analyses on squid ink powder. The moisture content of squid ink powder was $4.43 \pm 0.29 \%$. The protein content of squid ink powder was $62.46 \pm 0.62 \%$. Squid ink powder fat content was $3.96 \pm 0.08 \%$. Ash analysis used to determine the total amount of minerals contained in one sample. Squid ink powder contained $9.29 \pm 0.05 \%$ of 
the total mineral content.

\subsection{DPPH assay}

From the result obtained, Table 2, showed that distilled water extract had the highest percentage value of DPPH inhibition $(94.87 \pm 4.87) \%$, followed by ethanol $(67.57 \pm 7.55) \%$, and hexane extract $(2.10 \pm$ $1.18) \%$. The result obtained showed that there is a significant difference at $\mathrm{P}<0.05$ between each solvent used.

Table 2. DPPH inhibitions (\%) of squid ink powder by using different solvents

\begin{tabular}{cc}
\hline Solvents & Results $(\%)$ \\
\hline Distilled water & $94.87 \pm 4.87^{\mathrm{c}}$ \\
Ethanol & $67.57 \pm 7.55^{\mathrm{b}}$ \\
Hexane & $2.10 \pm 1.18^{\mathrm{a}}$ \\
\hline
\end{tabular}

Values are means $\pm \mathrm{SD}(\mathrm{n}=3)$. For each result, values followed with different letters $(a, b, c)$ are significantly different at $\mathrm{P}<0.05$.

\subsection{Ferric reducing antioxidant power (FRAP) assay}

Table 3. Ferric-reducing power of squid ink powder with different solvents

\begin{tabular}{cc}
\hline Solvents & Results $(\mu \mathrm{mol} \mathrm{Fe}(\mathrm{II}) / \mathrm{g})$ \\
\hline Distilled water & $929.67 \pm 2.31^{\mathrm{c}}$ \\
Ethanol & $201.00 \pm 26.29^{\mathrm{b}}$ \\
Hexane & $79.67 \pm 12.66^{\mathrm{a}}$ \\
\hline
\end{tabular}

Values are means $\pm \mathrm{SD}(\mathrm{n}=3)$. For each result, values followed with different letters $(a, b, c)$ are significantly different at $\mathrm{P}<0.05$.

FRAP value of distilled water extract from squid ink powder was the highest $(929.67 \pm 2.31) \mu \mathrm{mol} F$ Fe (II) per $\mathrm{g}$ of sample extract, followed by ethanol extract (201.00 $\pm 26.29) \mu \mathrm{mol} \mathrm{Fe}$ (II) per g of sample extract, and lastly hexane extract $(79.67 \pm 12.66) \mu \mathrm{mol} F$ Fe (II) per $\mathrm{g}$ of sample extract (Table 3). Each of value obtained showed the difference of each extraction solvent used. The results also indicate that all extracts of squid ink are able to act as a reducing agent which provides electron for stability.

\subsection{Antimicrobial activity}

The result showed that the squid ink powder extracts exhibited antimicrobial activity on selected Gram positive and Gram negative microorganism (Table 4). Bacillus subtilis and Staphylococcus aureus both were Gram positive bacteria while Salmonella $s p$ and Escherichia coli were Gram negative bacteria. Each of these bacteria was responsible for some food borne illnesses that affected human lives (Adams and Moss, 1995). Distilled water extract and ethanol extract both showed inhibition area after $16 \pm 2$ hours of incubation. However, there was no inhibition area formed around the discs with hexane extract after the incubation period.

\subsection{Total plate count}

From the result obtained, it showed that the fresh squid ink microbial content was $1.254 \times 10^{3}$ colony forming unit per gram of sample (Table 5). The microbial content in fresh squid ink was much lower that microbiological standard value stated in Food Act 1983 and Regulation 1985, (Fifteenth schedule, Regulation 39, Table 1), where the value stated for fish and fish product is $10^{6}$ per gram sample after incubation at $37^{\circ} \mathrm{C}$ for 48 hours.

Table 5. Total plate count of fresh squid ink and microbiological standard value

\begin{tabular}{cc}
\hline Sample & Result \\
\hline Fresh Squid Ink & $1.254 \times 10^{3} \mathrm{CFU} / \mathrm{g}$ \\
\hline
\end{tabular}

\section{Discussion}

The sample initially was in dry powdered form thus the moisture content is not very high. Moisture content in a food sample associated with the amount of free water present in food. This is determined by water activity value and from it, will indicate the food either has low or high-water activity. The amount of protein content in squid ink powder could be considered as high. Sea

Table 4. Antimicrobial activities of Gram positive and Gram negative bacteria with different extraction solvents of squid ink powder

\begin{tabular}{lccccc}
\hline Microorganism & $\begin{array}{c}\text { D. water } \\
\text { extract }\end{array}$ & $\begin{array}{c}\text { Ethanol } \\
\text { extract }\end{array}$ & $\begin{array}{c}\text { Hexane } \\
\text { extract }\end{array}$ & +ve control & -ve control \\
\hline Bacillus subtilis & $7.5 \mathrm{~mm}$ & $15 \mathrm{~mm}$ & Nil & $27 \mathrm{~mm}$ & Nil \\
Staphylococcus aureus & $8 \mathrm{~mm}$ & $11 \mathrm{~mm}$ & Nil & $28 \mathrm{~mm}$ & Nil \\
Salmonella sp. & $7 \mathrm{~mm}$ & $9 \mathrm{~mm}$ & Nil & $28 \mathrm{~mm}$ & Nil \\
Escherichia coli & $8.5 \mathrm{~mm}$ & $8.5 \mathrm{~mm}$ & Nil & $17.5 \mathrm{~mm}$ & Nil \\
\hline
\end{tabular}


products like squid generally contained a high amount of protein where the majority of it composed with myofibrilar protein $(80 \%)$, followed by myoplastic protein $(12-20 \%)$ and the least was myostroma protein (2 $-3 \%$ ) which composed of collagen (Okuzumi and Fujii, 2000). The ability of the protein to function as an ingredient in food products depends on their functional properties such as amino acid composition and environmental factors including $\mathrm{pH}$, temperature and ions present (Geirsdottir et al., 2011). The value of fat content in squid ink powder is slightly higher compared with raw squid which was about 1.0 to $2.0 \%$, where the value considered lowest among all types of seafood (Okuzumi and Fujii, 2000). Seafood contains various amounts of minerals due to minerals concentration in seawater contribute to it via food chain generally. The mineral content of squid and other seafood varies according to their species, environment, habitat, and maturity (Okuzumi and Fujii, 2000).

Squid ink did possess antioxidant activity. Removal of melanin from squid ink did not affect the antioxidant properties of squid ink where it showed valued when tested with several assays including DPPH assay. The radical scavenging activity of melanin free squid ink was $179.6 \pm 2.1 \%$ (Vate and Benjakul, 2013). Squid ink polysaccharide also possessed antioxidant ability from the scavenging ability of the sample with DPPH radicals (Luo and Liu, 2013).

Water extraction of squid ink powder gave out the highest value in total antioxidant activity DPPH assay compared with ethanol extraction and hexane extraction. Several studies reported that solvents with different polarity played a significant role in affecting the antioxidant activity. The solvents used as well as combination and concentration in extraction process influenced the type, yield, and potency of the antioxidant compounds (O’Sullivan et al., 2013).

Higher content of antioxidant has been found higher in more polar solvents (O'Sullivan et al., 2013). Oroian and Escriche (2015) explained that extraction yield increased with increasing polarity of solvents used with addition combination of water and organic solvent might facilitate the extraction of a compound that soluble in both polar and non-polar solvents.

From this analysis, it showed that there is a significant difference at $\mathrm{P}<0.05$ between the three solvent extracts of squid ink powder (Table 3). These solvents with different polarity were used to extract the antioxidant compound from squid ink powder. The selection of an appropriate extraction technique considers not only the different polarity, but also the cost, extraction time, the volume of solvent used etc. (Clara Grosso et al., 2015). From the results, water extraction has the highest value compared to ethanol and hexane extracts. Thus, it showed that the polar solvent has a high affinity in extracting out the antioxidant compound from the sample.

Both Gram positive and Gram negative bacteria showed susceptibility towards different extracts of squid ink powder, where the inhibition zone ranging from 7 $\mathrm{mm}$ to $8.5 \mathrm{~mm}$ for distilled water extract and from 8.5 $\mathrm{mm}$ to $15 \mathrm{~mm}$ for ethanol extract. The inhibition zone for positive control, gentamicin was ranged from $17.5 \mathrm{~mm}$ to $28 \mathrm{~mm}$. Antimicrobial activity had been reported from various parts of cephalopod. Squid (Loligo duvauceli) showed antimicrobial activity on E. coli and $S$. aureus from its accessory nidamental gland with inhibition range of $7 \mathrm{~mm}$ (Gomathi et al., 2010). Fresh squid ink extract of Loligo duvauceli did present antimicrobial properties on $E$. coli with inhibition range was $11 \mathrm{~mm}$ (Girija et al., 2012). The result recorded from this study showed that water extract of squid ink powder, as well as ethanol extract, presented inhibition zone on all bacteria used in this analysis. Ethanol extract of squid ink also showed antimicrobial activity from selected bacteria while hexane extract also reported exhibiting the same properties (Girija et al., 2012).

\section{Conclusion}

Protein is the major compound in squid ink powder due to its highest percentage in the proximate analysis while there is a low amount of fat, moisture, and ash. For microbial content analysis, fresh squid ink was used since it was a raw material and it was also considered as a waste product. The result showed microbial content was below from standard value of fisheries products as stated in Food Act 1983 and Regulation 1985.In total antioxidant activity determination for both DPPH assay and FRAP method, results showed that water extract of squid ink powder gave the highest value, followed by ethanol extract and lastly hexane extract. The result showed that there was a significant difference $(p<0.05)$ between each solvent for both antioxidant assays. The same result could be seen in the antimicrobial activity determination assay where the range of inhibition zone was around $7 \mathrm{~mm}$ to $15 \mathrm{~mm}$.

\section{Conflict of Interest}

We declare that we have no conflict of interest. 


\section{Acknowledgments}

This material is upon work supported by a grant number 304/PTEKIND/6312124 and 1001/ PTEKIND/812176 obtained from Universiti Sains Malaysia (USM).

\section{References}

Adams, M.R. and Moss, M.O. (1995). Food Microbiology. $1^{\text {st }}$ ed, p. 156-209. Cambridge: The Royal Society of Chemistry.

American Dietetic Association. (2010). Antioxidants. Eat Right Pamphlet. United States

AOAC. (2000). Official Methods of Analysis. Association of Official Analytical Chemists. USA: AOAC.

Benzie, I.F. and Strain, J.J. (1996). The ferric reducing ability of plasma (FRAP) as a measure of "antioxidant power": the FRAP assay. Analytical Biochemistry, 239(1), 70-76. https:// doi.org/10.1006/abio.1996.0292.

Cencic, A. and Chingwaru, W. (2010). The Role of Functional Foods, Nutraceuticals, and Food Supplements in Intestinal Health. Nutrients, 2(6), 611-625.

Clinical and Laboratory Standards Institute. (2014). Performance Standards for Antimicrobial Disk Susceptibility Tests. Approved Standard-Eleventh Edition. Vol. 32. USA: CLSI

Derby, C.D. (2014). Cephalopod ink: production, chemistry, functions, and applications. Marine Drugs, 12(5), 2700-2730.

Geirsdottir, M., Sigurgisladottir, S., Hamaguchi, P.Y., Thorkelsson, G., Johannsson, R., Kristinsson, H.G. and Kristjansson, M.M. (2011). Enzymatic Hydrolysis of blue whiting (Micromesistius poutassou): functional and bioactive properties. Journal of Food Science, 76(1), C14-C20.

Girija, S., Priyadharshini, V., Suba, P., Hariprasad, P. and Raguraman, R. (2012). Antibacterial effect of squid ink on ESBL producing strains of Escherichia coli and Klebsiella pneumoniae. Indian Journal of Geo-Marine Sciences, 41(4), 338-343.

Girija, S., Suba, P., Hariprasad, G. and Raghuraman, R. (2014). A novel study on the antibacterial effect of the crude squid ink extracts from the Indian squid against four bacterial pathogens isolated from carious dentine. International Journal of Current Microbiology and Applied Sciences, 3(4), 904-911.

Gomathi, P., Nair, J.R. and Sherief, P.M. (2010).
Antibacterial activity in the accessory nidamental gland extracts of the Indian squid, Loligo duvauceli Orbigny. Indian Journal of Marine Sciences, 39(1), 100-104.

Clara Grosso, C., Valentão, P., Ferreres, F. and Andrade, P.B. (2015). Alternative and Efficient Extraction Methods for Marine-Derived Compounds. Marine Drugs, 13, 3182-3230.

Ikram, E.H.K., Eng, K.H., Jalil, A.M.M., Ismail, A., Idris, S., Azlan, A. and Mokhtar, R.A.M. (2009). Antioxidant capacity and total phenolic content of Malaysian underutilized fruits. Journal of Food Composition and Analysis, 22(5), 388-393.

Liu, H., Luo, P., Chen, S. and Shang, J. (2011). Effects of Squid Ink on Growth Performance, Antioxidant Functions and Immunity in Growing Broiler Chickens. Asian-Australasian Journal of Animal Sciences, 24(12), 1752-1756.

Luo, P. and Liu, H. (2013). Antioxidant ability of squid ink polysaccharides as well as their protective effects on deoxyribonucleic acid DNA damage in vitro. African Journal of Pharmacy and Pharmacology, 7 (21), 1382-1388.

Ministry of Health Malaysia. (2010). Malaysian Dietary Guidelines. Retrived from Ministry of Health Malaysia website: http://dg.cnsoc.org/upload/ affix/20140818104029708.pdf

O’Sullivan, A.M., O'Callaghan, Y.C., O’Grady, M.N., Hayes, M., Kerry, J.P. and O'Brien, N.M. (2013). The effect of solvents on the antioxidant activity in Caco-2 cells of Irish brown seaweed extracts prepared using accelerated solvent extraction (ASE®). Journal of Functional Foods, 5(2), 940948.

Okuzumi, M. and Fujii, T. (2000). Nutritional and Functional Properties of Squid and Cuttlefish. $1^{\text {st }}$ ed. Tokyo, Japan: National Cooperative Association of Squid Processor.

Oroian, M. and Escriche, I. (2015). Antioxidants: Characterization, natural sources, extraction and analysis. Food Research International, 74, 10-36.

Rubaie, Z.M., Idris, M.H., Hena, A., Kamal, M. and King, W.S. (2011). Diversity of Cephalopod from Selected Division of Sarawak, Malaysia. International Journal on Advanced Science, Engineering and Information Technology, 2(4), 279281.

Sánchez-Moreno, C., Larrauri, J.A. and Saura-Calixto, F. (1998). A procedure to measure the antiradical efficiency of polyphenols. Journal of the Science of 
Food and Agriculture, 76(2), 270-276.

Tee, E.S. (2013). Functional foods for health promotion.

Retreived from Ministry of Health Malaysia website: http://jknkelantan.moh.gov.my

The European Scientific Community (Eds.). (2010). What are functional foods. In Functional Foods, p. 7 8. Luxembourg: Publications office of European Union

Vate, N.K. and Benjakul, S. (2013). Antioxidative activity of melanin-free ink from splendid squid (Loligo formosana). International Aquatic Research, 5(1), 9. https://doi.org/10.1186/2008-6970-5-9. 